\title{
What are the gaps in quality measurement for lung cancer surgery?
}

\author{
Felix G. Fernandez, MD, MSc
}

\footnotetext{
From the Section of Thoracic Surgery, Emory University, Atlanta, Ga.

Work discussed in this editorial is supported by grant R01 HS022279 from the Agency for Healthcare Research and Quality. The content is solely the responsibility of the author and does not necessarily represent the official views of the Agency for Healthcare Research and Quality.

Disclosures: Author has nothing to disclose with regard to commercial support.

Received for publication June 9, 2017; accepted for publication June 19, 2017; available ahead of print July 25, 2017.

Address for reprints: Felix G. Fernandez, MD, MSc, The Emory Clinic, 1365 Clifton Rd, NE, Suite A2214, Atlanta, GA 30322 (E-mail: felix.fernandez@emoryhealthcare.org).

J Thorac Cardiovasc Surg 2017;154:1395-6

$0022-5223 / \$ 36.00$

Copyright (c) 2017 by The American Association for Thoracic Surgery

http://dx.doi.org/10.1016/j.jtcvs.2017.06.048
}

In this month's edition of The Journal of Thoracic and Cardiovascular Surgery, Brandt and colleagues ${ }^{1}$ provide a timely expert opinion on the elements that define quality in lung cancer surgery. There are several indicators to consider in defining quality in lung cancer surgery, including patient selection, safety, oncologic efficacy, cost and resource utilization, and long-term survival and quality of life. These indicators have different importance to different stakeholders and can be challenging to define and measure.

From a patient-centered perspective, the most important indicators are the outcome measures of long-term survival and quality of life. These data are not readily obtained, however, and they remain critical gaps in our measurement of quality. Operative morbidity and mortality have therefore been used as measures of quality for lung cancer surgery. The Society of Thoracic Surgeons has developed a composite score of morbidity and mortality to rank program performance for lobectomy. ${ }^{2}$ This composite score assesses the safety of surgery; however, it does not measure the adequacy of the oncologic resection. In fact, it is possible to perform lobectomy for lung cancer with incomplete resections and no lymph node evaluation and still appear to be a high performer if the risk-adjusted morbidity and mortality are low. Process measures, such as preoperative staging, completeness of resection, and adequacy of lymph node assessment, thus become critical to measure. Tracking such process measures is important, because adherence has been associated with long-term survival. ${ }^{3}$

To continue to improve the quality of lung cancer operations, we must get better at measuring outcomes that matter to patients. Critical to this is the ascertainment of long-term survival and the assessment of patient-reported outcomes. Although many institutions track survival, until recently survival data have not been available in our most robust database, the Society of Thoracic Surgeons General Thoracic Surgery Database. Recent initiatives have linked centered care.

\section{References}

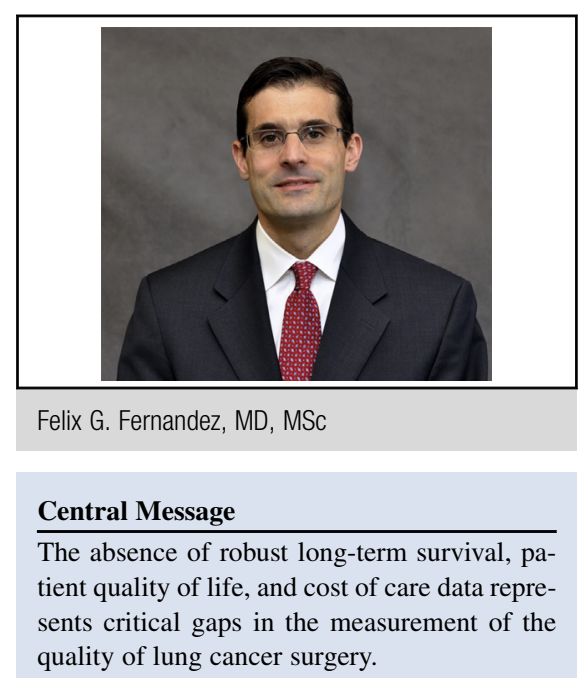

See Article page 1397.

a subset of lung cancer surgeries in the General Thoracic Surgery Database with Medicare data for longitudinal follow-up, and centers submitting to the database are now required to track survival for lung and esophageal cancer resections. ${ }^{4}$ In addition, initiatives are underway to determine how best to incorporate patient-reported outcomes data into the Society of Thoracic Surgeons database. ${ }^{5}$ As patients and providers face critical treatment decisions, survival and quality-of-life data will facilitate delivery of more patient-

Finally, of importance to payers is the cost of care. The cost of lung cancer surgery varies according to patient and treatment factors. ${ }^{6}$ As noted by Brandt and colleagues, ${ }^{1}$ more expensive new or emerging technologies must provide a benefit to the patient relative to the current standard of care, otherwise they do not add value. Although cost data are difficult to obtain, linking to administrative data and partnering with third-party payers on quality initiatives may help us measure and contain costs. As defined by Porter, ${ }^{7}$ value in health care is defined by quality over costs. In lung cancer surgery, we must strive for care that maximizes survival and quality of life while making efficient use of limited resources.

1. Brandt WS, Isbell JM, Jones DR. Defining quality in the surgical care of lung cancer patients. J Thorac Cardiovasc Surg. 2017;154:1397-403.

2. Kozower BD, O'Brien SM, Kosinski AS, Magee MJ, Dokholyan R, Jacobs JP et al. The Society of Thoracic Surgeons composite score for rating program 
performance for lobectomy for lung cancer. Ann Thorac Surg. 2016;101:1379-86; discussion 1386-7.

3. Samson P, Crabtree T, Broderick S, Kreisel D, Krupnick AS, Patterson GA, et al. Quality measures in clinical stage I non-small cell lung cancer: improved performance is associated with improved survival. Ann Thorac Surg. 2017;103:303-11. 4. Fernandez FG, Furnary AP, Kosinski AS, Onaitis MW, Kim S, Boffa D, et al. Longitudinal follow-up of lung cancer resection from the Society of Thoracic Surgeons General Thoracic Surgery Database in patients 65 years and older. Ann Thorac Surg. 2016;101:2067-76.
5. Khullar OV, Rajaei MH, Force SD, Binongo JN, Lasanajak Y, Robertson S, et al. Pilot study to integrate patient reported outcomes after lung cancer operations into the Society of Thoracic Surgeons database. Ann Thorac Surg. 2017;104:245-53.

6. Medbery RL, Perez SD, Force SD, Gillespie TW, Pickens A, Miller DL, et al. Video-assisted thoracic surgery lobectomy cost variability: implications for a bundled payment era. Ann Thorac Surg. 2014;97:1686-92; discussion 1692-3.

7. Porter ME. What is value in health care? N Engl J Med. 2010;363:2477-81. 